\title{
AN IMPROVED METHOD FOR DETERMINING $\beta$-GLUCAN IN WORT AND BEER BY USE OF CALCOFLUOR
}

\author{
by \\ KIM G. JØRGENSEN \\ Department of Biotechnology, Carlsberg Research Laboratory, \\ Gamle Carlsberg Vej 10, DK-2500 Copenhagen Valby
}

Keywords: Fluorescence, routine analysis, dimethylsulfoxid, $\beta$-glucanase

An improved method for the determination of $\beta$-glucan in beer and wort employing the fluorochrome Calcofluor is described. Dimethylsulfoxid $(20 \%(\mathrm{v} / \mathrm{v}))$ was used to obtain a reproducible binding ratio of Calcofluor to $\beta$-glucan. The formed complex was precipitated by $77 \%$ ethanol and separated by centrifugation. The precipitate was dissolved in a glycine $/ \mathrm{NaOH}$ buffer at $\mathrm{pH}=10.0$ and fluorescence was measured in a spectrofluorometer. The method correlates well with the established ammoniumsulphate precipitation method for $\beta$-glucan for a wide range of beer and wort samples. Treatment of beers and worts with pure $\beta$-glucanase gave a low background fluorescence, thus indicating a high specificity of the method. From dialysis experiments it was found that low molecular $\beta$-glucans $<10,000$ daltons only gave a slight binding to Calcofluor. The analysis is suitable for routine control in a brewery, allowing an output of at least 50 samples per day per person.

\section{INTRODUCTION}

$\beta$-glucans are the major structural component of barley endosperm cell walls (6). If not sufficiently degraded in the malt house, high molecular weight $\beta$-glucans can persist in wort and beer, causing increased viscosity and delayed filtration $(3,7,9,13)$, as well as precipitate in the final beer (14).
Traditionally the quantity of $\beta$-glucans in wort and beer are estimated by precipitation with ammoniumsulphate $(5,12)$, but analogous methods have been described using $\mathrm{CuSO}_{4}$ (11) or cold ethanol (3) for precipitation. These procedures, involving selective precipitation, purification, acid hydrolysis and determination of released glucose, are laborious and time consuming and

Abbreviations: AMS-method $=\left(\mathrm{NH}_{4}\right)_{2} \mathrm{SO}_{4}$ precipitation method; CEP-method $=$ Calcofluor/ethanol precipitation method; DMSO = Dimethylsulfoxid; Mixed linked $(1 \rightarrow 3),(1 \rightarrow 4)-\beta$-D-glucans, in the present communication referred to as $\beta$-glucans; $(1 \rightarrow 3)$, $(1 \rightarrow 4)-\beta$-D-glucan 4-endo-hydrolase (EC: 3.2 .1 .73$)$ referred to as $\beta$-glucanase. 
are not suitable as a routine analysis in a brewery. Therefore, viscosity measurement of wort and beer is the only practical alternative, giving only an indication of $\beta$-glucan content. Recently, a spectrofluorometric method has been described by JENSEN and AASTRUP (10), based on the ability of the fluorochrome Calcofluor specifically to bind $\beta$-glucan $(15,16,17)$. This preliminar method has been used to measure the content of $\beta$-glucan in barley, malt, wort and beer. Within a narrow range of test samples a good correlation between the fluorescence measurement and the traditional AMS-method was found for wort and beer.

In the present paper the method described by JENSEN and AASTRUP (10) has been investigated and improved. Physical and chemical factors affecting the binding between Calcofluor and $\beta$-glucan were studied.

\section{MATERIALS AND METHODS}

\subsection{Material}

\subsubsection{Beer}

The investigations were carried out on 56 beer samples (Table I), 46 of which were commercially available and 10 produced at a pilot brew- ery. P. HaRTLEy, The Central Laboratory of the Carlsberg Brewery, and S. AASTRUP, Department of Brewing Chemistry, Carlsberg Research Laboratory, kindly supplied the beer samples.

\subsubsection{Wort}

The analysed samples were 16 production worts from the Carlsberg brewery and 8 congress worts (Table II), which were derived from Triumph and Minerva barley. The congress worts were prepared at the Central Laboratory by J.C. LORENZEN according to the method by the Analytical Committee of the European Brewery Convention (2). The malt samples used for the congress worts represent various degrees of modification (Table II). Modification of the malt samples was measured as described by AASTRUP et al.(1).

\subsection{Storage of beer and wort samples}

Beer and wort samples were kept at $0{ }^{\circ} \mathrm{C}$ and $0.1 \mathrm{~g} \cdot \mathrm{l}^{-1}$ Thimerosal (Natrium ethylmercurithiosalisylat) was added to the wort samples to avoid microbial infections.

Table I.

Beer Analysis.

\begin{tabular}{cllcccc}
\hline $\begin{array}{c}\text { Reference } \\
\text { No. }\end{array}$ & $\begin{array}{c}\text { Origin of } \\
\text { beer }\end{array}$ & Type $^{\mathrm{b}}$ & $\begin{array}{c}\text { Viscosity } \\
(\mathrm{cP})\end{array}$ & $\begin{array}{c}\text { Fluorescence } \\
\text { intensity } \\
(\mathrm{mV})\end{array}$ & $\begin{array}{c}\text { AMS } \\
\text { precipitate } \\
\left(\mathrm{mg} \cdot \mathrm{l}^{-1}\right)\end{array}$ & $\begin{array}{c}\text { CEP-estimate of } \\
\text { AMS-method } \\
\left(\mathrm{mg} \cdot \mathrm{l}^{-1}\right)\end{array}$ \\
\hline 1 & Denmark & II & 1.24 & $30 \pm 0$ & 0 & 0 \\
2 & Sweden & II & 1.35 & $80 \pm 3$ & $8 \pm 2$ & 0 \\
3 & Denmark & IV & 1.51 & $104 \pm 1$ & $9 \pm 2$ & 0 \\
4 & W. Germany & II & 1.56 & $172 \pm 3$ & $13 \pm 0$ & $18 \pm 2$ \\
5 & Denmark & III & 1.59 & $151 \pm 2$ & $20 \pm 3$ & $7 \pm 1$ \\
6 & - & II & 1.48 & $195 \pm 3$ & $28 \pm 1$ & $30 \pm 2$ \\
7 & - & IV & 1.84 & $117 \pm 0$ & $34 \pm 0$ & 0 \\
8 & Holland & II & 1.51 & $128 \pm 4$ & $42 \pm 1$ & 0 \\
9 & Denmark & I & 1.39 & $203 \pm 4$ & $53 \pm 6$ & $34 \pm 2$ \\
10 & Canada & I & 1.42 & $166 \pm 8$ & $57 \pm 4$ & $15 \pm 4$ \\
11 & Malawi & IV & 1.61 & $292 \pm 8$ & $74 \pm 1$ & $80 \pm 4$ \\
12 & Denmark & I & 1.35 & $328 \pm 4$ & $78 \pm 1$ & $98 \pm 2$ \\
13 & - & I & 1.79 & $374 \pm 10$ & $84 \pm 1$ & $121 \pm 5$ \\
& & & & & & \\
(cont.)
\end{tabular}


Table I. (contd.)

Beer Analysis.

\begin{tabular}{|c|c|c|c|c|c|c|}
\hline $\begin{array}{c}\text { Reference } \\
\text { No. }\end{array}$ & $\begin{array}{l}\text { Origin of } \\
\text { beer }^{\mathrm{a}}\end{array}$ & Type ${ }^{b}$ & $\begin{array}{l}\text { Viscosity } \\
\text { (cP) }\end{array}$ & $\begin{array}{l}\text { Fluorescence } \\
\text { intensity } \\
(\mathrm{mV})\end{array}$ & $\begin{array}{c}\text { AMS } \\
\text { precipitate } \\
\left(\mathrm{mg} \cdot \mathrm{l}^{-1}\right)\end{array}$ & $\begin{array}{l}\text { CEP-estimate of } \\
\text { AMS-method } \\
\left(\mathrm{mg} \cdot \mathrm{l}^{-1}\right)\end{array}$ \\
\hline 14 & - & I & 1.38 & $359 \pm 1$ & $88 \pm 1$ & $114 \pm 1$ \\
\hline 15 & - & $\mathrm{II}^{\mathrm{d}}$ & 1.59 & $401 \pm 13$ & $89 \pm 10$ & $135 \pm 7$ \\
\hline 16 & - & II & 1.53 & $371 \pm 3$ & $91 \pm 2$ & $120 \pm 2$ \\
\hline 17 & - & II & 1.50 & $307 \pm 3$ & $94 \pm 2$ & $87 \pm 2$ \\
\hline 18 & - & II & 1.59 & $294 \pm 10$ & $101 \pm 3$ & $81 \pm 5$ \\
\hline 19 & - & III & 1.88 & $424 \pm 20$ & $104 \pm 2$ & $147 \pm 10$ \\
\hline 20 & - & IV & 1.59 & $421 \pm 9$ & $104 \pm 9$ & $146 \pm 5$ \\
\hline 21 & - & II & 1.52 & $420 \pm 10$ & $105 \pm 1$ & $145 \pm 5$ \\
\hline 22 & W. Germany & IV c & 3.41 & $396 \pm 0$ & $112 \pm 0$ & $133 \pm 0$ \\
\hline 23 & Denmark & II & 1.53 & $470 \pm 20$ & $115 \pm 1$ & $171 \pm 10$ \\
\hline 24 & - & I & 1.37 & $376 \pm 6$ & $118 \pm 1$ & $123 \pm 3$ \\
\hline 25 & - & III & 1.55 & $232 \pm 2$ & $120 \pm 1$ & $49 \pm 1$ \\
\hline 26 & - & IV & 1.64 & $555 \pm 5$ & $137 \pm 5$ & $214 \pm 3$ \\
\hline 27 & - & II & 2.08 & $368 \pm 4$ & $138 \pm 4$ & $118 \pm 2$ \\
\hline 28 & . & II d $^{d}$ & 1.55 & $560 \pm 25$ & $145 \pm 5$ & $217 \pm 13$ \\
\hline 29 & - & I & 1.32 & $405 \pm 20$ & $153 \pm 7$ & $137 \pm 10$ \\
\hline 30 & - & II & 1.55 & $416 \pm 4$ & $157 \pm 1$ & $143 \pm 2$ \\
\hline 31 & - & IV & 1.74 & $640 \pm 25$ & $171 \pm 5$ & $258 \pm 13$ \\
\hline 32 & - & $V^{d}{ }^{d}$ & 1.53 & $508 \pm 24$ & $178 \pm 13$ & $190 \pm 12$ \\
\hline 33 & - & II & 1.60 & $685 \pm 15$ & $192 \pm 5$ & $281 \pm 8$ \\
\hline 34 & - & IV & 1.95 & $535 \pm 5$ & $192 \pm 4$ & $204 \pm 3$ \\
\hline 35 & - & I & 1.35 & $508 \pm 3$ & $193 \pm 1$ & $190 \pm 2$ \\
\hline 36 & - & II & 1.50 & $453 \pm 18$ & $200 \pm 20$ & $162 \pm 9$ \\
\hline 37 & - & III & 1.68 & $370 \pm 8$ & $203 \pm 0$ & $119 \pm 4$ \\
\hline 38 & - & III & 1.67 & $425 \pm 15$ & $204 \pm 9$ & $148 \pm 8$ \\
\hline 39 & - & IV & 2.31 & $440 \pm 21$ & $205 \pm 2$ & $155 \pm 11$ \\
\hline 40 & - & IV & 1.87 & $643 \pm 16$ & $213 \pm 4$ & $259 \pm 8$ \\
\hline 41 & - & II & 1.62 & $488 \pm 3$ & $218 \pm 1$ & $180 \pm 2$ \\
\hline 42 & - & IV & 1.67 & $415 \pm 4$ & $226 \pm 1$ & $142 \pm 2$ \\
\hline 43 & - & II & 1.67 & $533 \pm 27$ & $235 \pm 1$ & $203 \pm 14$ \\
\hline 44 & - & $\mathrm{II}^{\mathrm{d}}$ & 1.62 & $703 \pm 26$ & $257 \pm 1$ & $290 \pm 13$ \\
\hline 45 & - & II d & 1.63 & $770 \pm 40$ & $262 \pm 4$ & $324 \pm 20$ \\
\hline 46 & W. Germany & $\mathrm{II}^{\mathrm{c}}$ & 1.64 & $655 \pm 10$ & $281 \pm 3$ & $265 \pm 5$ \\
\hline 47 & Denmark & IV & 1.97 & $750 \pm 0$ & $310 \pm 3$ & $314 \pm 0$ \\
\hline 48 & - & $\mathrm{II}^{\mathrm{c}}$ & 1.76 & $760 \pm 10$ & $327 \pm 1$ & $319 \pm 5$ \\
\hline 49 & - & II d $^{d}$ & 1.75 & $788 \pm 18$ & $350 \pm 3$ & $334 \pm 9$ \\
\hline 50 & - & II d $^{d}$ & 1.71 & $845 \pm 10$ & $380 \pm 1$ & $363 \pm$ \\
\hline 51 & - & II d $^{d}$ & 1.67 & $978 \pm 63$ & $381 \pm 8$ & $431 \pm 32$ \\
\hline 52 & - & II $^{c}$ & 1.76 & $898 \pm 18$ & $391 \pm 5$ & $390 \pm 9$ \\
\hline 53 & - & III & 1.76 & $778 \pm 18$ & $393 \pm 5$ & $328 \pm 9$ \\
\hline 54 & - & $\mathrm{II}^{\mathrm{d}}$ & 1.76 & $1005 \pm 0$ & $407 \pm 21$ & $445 \pm 0$ \\
\hline 55 & - & III & 1.87 & $973 \pm 20$ & $421 \pm 9$ & $428 \pm 10$ \\
\hline 56 & - & III $^{c}$ & 1.98 & $1053 \pm 25$ & $498 \pm 5$ & $469 \pm 13$ \\
\hline
\end{tabular}

a: Beer produced in Denmark are from 11 different breweries,

b: types of beer classified by I: light pilsner type, extract of wort 7-8 ${ }^{\circ}$, II: pilsner type, extract of wort 10-11 ${ }^{\circ}$, III: pilsner type, extract of wort 12-14 $\mathrm{OP}$, IV: strong beer, extract of wort 15-19 ${ }^{\circ}$,

c: all malt beer,

d: pilot brewery beer. 
Table II.

Wort Analysis

\begin{tabular}{|c|c|c|c|c|c|}
\hline $\begin{array}{c}\text { Reference } \\
\text { No. }\end{array}$ & $\begin{array}{c}\text { Ekstract content } \\
\left({ }^{\circ} \mathrm{P}\right)\end{array}$ & $\begin{array}{c}\text { Viscosity } \\
\text { (cP) }\end{array}$ & $\begin{array}{l}\text { Fluorescence } \\
\text { intensity } \\
(\mathrm{mV})\end{array}$ & $\begin{array}{c}\text { AMS } \\
\text { precipitate } \\
\left(\mathrm{mg} \cdot \mathrm{l}^{-1}\right)\end{array}$ & $\begin{array}{l}\text { CEP-estimate of } \\
\text { AMS-method } \\
\left(\mathrm{mg} \cdot \mathrm{I}^{-1}\right)\end{array}$ \\
\hline $1^{a}$ & 8.5 & 1.69 & $118 \pm 2$ & $17 \pm 1$ & $70 \pm 2$ \\
\hline $2^{a}$ & 8.5 & 1.82 & $151 \pm 3$ & $20 \pm 1$ & $98 \pm 3$ \\
\hline $3^{a}$ & 8.5 & 1.69 & $169 \pm 3$ & $37 \pm 1$ & $113 \pm 3$ \\
\hline $4^{b}$ & 10.7 & 1.67 & $165 \pm 10$ & $73 \pm 3$ & $109 \pm 10$ \\
\hline $5^{a}$ & 8.5 & 1.93 & $294 \pm 5$ & $103 \pm 2$ & $217 \pm 5$ \\
\hline $6^{b}$ & 6.5 & 1.44 & $261 \pm 7$ & $124 \pm 2$ & $190 \pm 7$ \\
\hline $7 \mathrm{~b}$ & 10.7 & 1.91 & $210 \pm 5$ & $156 \pm 3$ & $147 \pm 5$ \\
\hline $8^{b}$ & 10.7 & 1.92 & $217 \pm 7$ & $159 \pm 2$ & $153 \pm 7$ \\
\hline $9 \mathrm{~b}$ & 10.7 & 1.94 & $239 \pm 11$ & $191 \pm 1$ & $171 \pm 11$ \\
\hline $10^{b}$ & 16.5 & 2.27 & $320 \pm 10$ & $231 \pm 3$ & $239 \pm 10$ \\
\hline $11^{\mathrm{b}}$ & 10.7 & 1.74 & $287 \pm 5$ & $262 \pm 8$ & $212 \pm 5$ \\
\hline $12^{b}$ & 10.7 & 1.82 & $363 \pm 1$ & $268 \pm 18$ & $275 \pm 1$ \\
\hline $13^{b}$ & 10.7 & 1.82 & $362 \pm 2$ & $275 \pm 20$ & $274 \pm 2$ \\
\hline $14^{a}$ & 8.5 & 1.75 & $473 \pm 9$ & $284 \pm 1$ & $367 \pm 9$ \\
\hline $15^{b}$ & 10.7 & 1.78 & $366 \pm 0$ & $292 \pm 3$ & $278 \pm 0$ \\
\hline $16^{b}$ & 10.7 & 1.89 & $388 \pm 8$ & $300 \pm 10$ & $296 \pm 8$ \\
\hline $17^{b}$ & 10.7 & 1.76 & $430 \pm 11$ & $425 \pm 2$ & $331 \pm 11$ \\
\hline $18^{b}$ & 12.7 & 1.86 & $452 \pm 13$ & $436 \pm 20$ & $350 \pm 13$ \\
\hline $19^{b}$ & 10.7 & 1.79 & $449 \pm 11$ & $480 \pm 16$ & $347 \pm 11$ \\
\hline $20^{b}$ & 10.7 & 1.72 & $615 \pm 10$ & $533 \pm 15$ & $487 \pm 10$ \\
\hline $21^{b}$ & 13.0 & 2.34 & $753 \pm 3$ & $680 \pm 21$ & $602 \pm 3$ \\
\hline 22 & 8.5 & 2.24 & $1055 \pm 15$ & $954 \pm 7$ & $855 \pm 15$ \\
\hline $23^{\circ}$ & 8.5 & 2.53 & $2580 \pm 50$ & $2044 \pm 17$ & $2134 \pm 50$ \\
\hline $24^{\mathrm{a}}$ & 8.5 & 4.96 & $4350 \pm 15$ & $3590 \pm 20$ & $3617 \pm 15$ \\
\hline
\end{tabular}

a: Congress wort: sample no 1, 3,14 and 23 are made from Triumph malt, germinated 3, 5, 7 and 9 days and modification was measured to $19,70,93$ and $99 \%$, respectively, samples No. 2, 5, 22 and 24 are made from Minerva malt, germinated 3, 5, 7 and 9 days and modification was measured to $17,62,88$ and $96 \%$, respectively.

b: Production worts from the Carlsberg brewery.

\subsection{Determination of $\beta$-glucan by the AMS- method}

The method of Preece and MacKenzie (12) modified by ERDAL and GJERTSEN (5) was used for the estimation of soluble $\beta$-glucan in beer and wort. The $\beta$-glucans were precipitated by $30 \mathrm{~g}$ $\left(\mathrm{NH}_{4}\right)_{2} \mathrm{SO}_{4}$ per $100 \mathrm{ml}$ beer or wort at $0{ }^{\circ} \mathrm{C}$ for 1 hour, centrifuged, and washed twice with $20 \%$ ethanol. The precipitate was redissolved in $1 \mathrm{~N}$ $\mathrm{H}_{2} \mathrm{SO}_{4}$ by boiling for $15 \mathrm{~min}$. Determination of the amount of reducing carbohydrate in the solution was carried out with the phenol/sulphuric acid method (5). Absorption was read at $490 \mathrm{~nm}$ with glucose as standard.

\subsection{Determination of $\beta$-glucan with the Calcofluor Ethanol Precipitation (CEP) method}

The CEP-method of JENSEN and AASTRUP (10) was first used, with a minor modification, using an ultrasonic treatment to dissolve the precipitate in the glycerol. In section 3 the following improved method has been developed: A Calcofluor (Polysciences Inc., Warrington, P.A., USA) solution of $1 \mathrm{~g} \cdot \mathrm{l}^{-1}$ of Calcofluor in a $40 \%$ $(\mathrm{v} / \mathrm{v})$ aqueous DMSO solution was thermostated at $20^{\circ} \mathrm{C} .1 \mathrm{ml}$ of decarbonated beer or $0.5 \mathrm{ml}$ wort at $20^{\circ} \mathrm{C}$ was mixed with $1 \mathrm{ml}$ or $0.5 \mathrm{ml} \mathrm{Calcofluor}$ solution for beer and wort, respectively, and kept 
at $20^{\circ} \mathrm{C}$ for $15 \mathrm{~min}$ for a complete reaction. The Calcofluor- $\beta$-glucan complex was precipitated with 8 or $4 \mathrm{ml} 96 \%$ ethanol for samples of beer or wort, respectively, and centrifuged for $10 \mathrm{~min}$ at $4000 \mathrm{rpm}$. The precipitate was washed with $2 \times 5$ $\mathrm{ml} 80 \%$ ethanol, using a Whirlimixer followed again by centrifugation. For fluorescence measurement the precipitated Calcofluor- $\beta$-glucan complex was dissolved in $5 \mathrm{ml} 0.5 \mathrm{M}$-Glycine/ $\mathrm{NaOH}$ buffer, $\mathrm{pH}=10.0$. After swelling in $30 \mathrm{~min}$ at room temperature the precipitate was dissolved by treatment in an ultrasonic bath for 10 min, followed by a brief mixing on the Whirlimixer.

Measurement of fluorescence intensity was performed by transferring the Calcofluor- $\beta$ glucan complex solubilized in glycine buffer to a $10 \times 10 \mathrm{~mm}$ quartz cuvette, recording fluorescence spectra at maximum excitation wavelength and emission. The equipment used was a JASCO spectrofluorometer (model: FP 550, Japan Spectroscopic Co. Ltd.) with a connected recorder. Maximum excitation was achieved at $363 \mathrm{~nm}$; emission maximum was found to 425 $\mathrm{nm}$. A constant output level of the fluorometer was ensured by calibration against a fluorescence standard block (Perkin Elmer, Beaconsfield, England).

\subsection{Viscosity determination}

Beer viscosity was measured with a Haake Kugelfall Viscosimeter (Haake, K.G., Berlin Steglitz, W. Germany) and wort viscosity on a Contraves Low Shear 100 Viscometer (Contraves A.G., Zurich, Switzerland).

\section{6. $\beta$-glucanase treatment of wort and beer}

As a check for unspecific binding of Calcofluor, samples of beer and wort were treated with pure $\beta$-glucanase. The enzyme was kindly supplied by B.S. ENEVOLDSEN and K. ERdal, Department of Brewing Chemistry, Carlsberg Research Laboratory. It was devoid of $\alpha$-amylase activity. $\beta$-glucanase activity was $4.7 \mathrm{U} \cdot \mathrm{ml}^{-1}$ at $\mathrm{pH}=6.5$. For $\beta$-glucanase treatment a sample of beer or wort was adjusted to $\mathrm{pH}=6.5$ with $2 \mathrm{~N}$ $\mathrm{NaOH}$ and $1 \mathrm{ml} 0.25 \mathrm{M}$-maleic-sodium-maleate buffer (containing $0.01 \%$ Thimerosal) and $100 \mu \mathrm{l}$ $\beta$-glucanase ( 0.5 Units) were added per $4 \mathrm{ml} \mathrm{sam}$ ple. The mixtures were incubated at $40^{\circ} \mathrm{C}$ for 24 hours and measured with the improved CEPmethod according to section 2.4 .

\subsection{Dialysis of beer and addition of carbohydrates}

$150 \mathrm{ml}$ beer was dialyzed against distilled water for 48 hours, using a standard cellulose tubing (cut off 10,000 - 12,000 daltons). The volume of the dialyzed samples were adjusted to 150 $\mathrm{ml}$ after evaporation of excess water with a hairdryer, and $0.1 \mathrm{~g} \cdot \mathrm{l}^{-1}$ Thimerosal was added. The dialyzed samples were mixed with solutions of "known" carbohydrate composition and analysed by the improved CEP-method (section 2.4). The following mixtures were made:

1. Dialyzed beer + concentrated $\beta$-glucanase treated beer (section 2.6), (concentrated $\beta$-glucanase treated beer was made by freeze drying and redissolving in half the original volume of water).

2. Dialyzed beer $+10 \%(w / v)$ aqueous solution of Corn Sirup, CPC 1924, (CPC Industriprodukter A/S, Holte Denmark).

3. Dialyzed beer $+20 \%(\mathrm{w} / \mathrm{v})$ aqueous solution of Corn Sirup, CPC 1924.

4. Dialyzed beer $+1 \%(w / v)$ aqueous solution of soluble starch, (E. Merck, Darmstadt, W. Germany, art No. 1252).

\section{RESULTS}

\subsection{Results obtained with the preliminary CEP- method of JENSEN and AASTRUP (10)}

The correlation between $\beta$-glucan content of beers estimated by the AMS- and CEP-methods as described by JENSEN and AASTRUP (10), was found to be unsatisfactory $(R=0.686)$ with the wide selection of beers (Figure 1). When beers of similar type were selected, correlation data were improved. Beers within type I and II (Table I, column 2) excluding those from the pilot brewery and beers brewed from all malt, gave a correlation coefficient of $R=0.830(\mathrm{~N}=21)$ between the AMS- and CEP-methods. In order to further improve the CEP-method, physical and chemical factors which might affect the $\beta$-glucan Cal- 


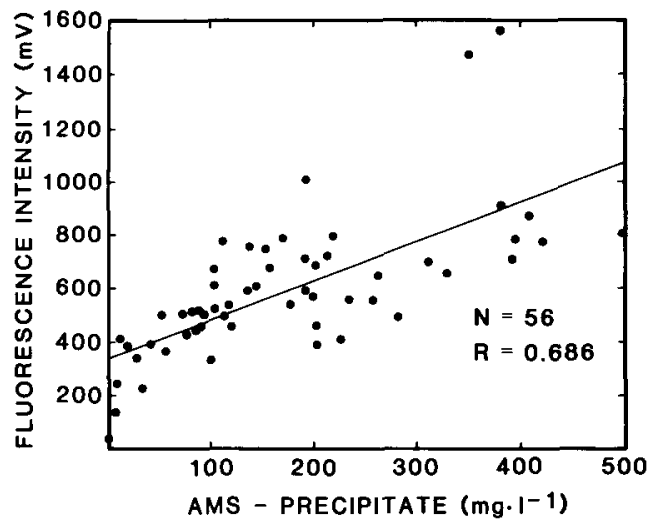

Figure 1. The relationship between $\beta$-glucan content in beer estimated by the AMS-method and CEP-method of JENSEN and AASTRUP (10). Material from Table I.

cofluor complex formation as well as unspecific binding, were systematically investigated.

\subsection{Physical and chemical factors influencing the analysis}

\subsubsection{The concentration of Calcofluor}

By increasing the concentration of Calcofluor added to beer, it was possible to increase the fluorescence intensity of the ethanol precipitate (Figure 2). Between 0 and $3 \mathrm{~g} \cdot \mathrm{l}^{-1}$ Calcofluor, a sigmoid relationship between concentration and fluorescence intensity was observed. Above 3

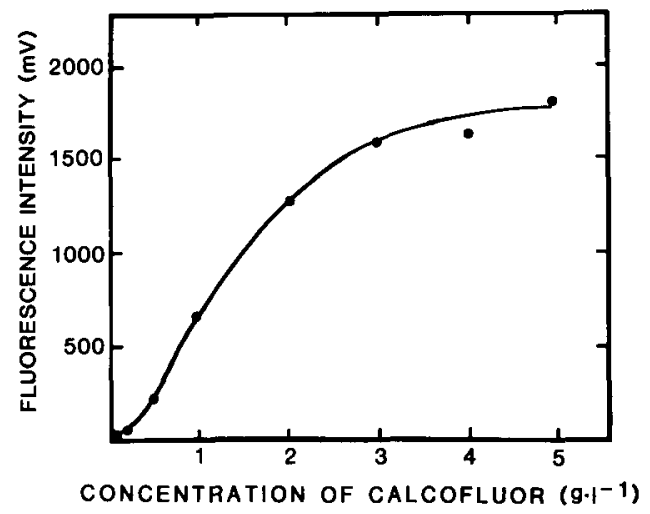

Figure 2. The effect of Calcofluor concentration on the fluorescence intensity of the Calcofluor- $\beta$-glucan ethanol precipitated complex from beer. Basic method according to JENSEN and AASTRUP (10). $\mathrm{g} \cdot \mathrm{l}^{-1}$ the response seems to reach a constant level. In order to investigate the effect of a higher Calcofluor concentration, a $4 \mathrm{~g} \cdot \mathrm{l}^{-1}$ aqueous solution was used instead of original $1 \mathrm{~g} \cdot \mathrm{l}^{-1}$ (section 2.4). For a subgroup of 45 beers representing all types, a poor correlation of $\mathrm{R}=0.509$ between the AMS-method and the modified CEP-method was found. Thus under these conditions increased levels of fluorochrome do not improve the method.

\subsubsection{The effect of $\mathrm{pH}$ on Calcofluor binding}

The $\mathrm{pH}$ values for all beer samples tested were found to vary between 4.0 and 4.8. The Calcofluor binding was slightly improved with the increase of $\mathrm{pH}$ at complex formation. $\mathrm{A} 1 \mathrm{~g} \cdot \mathrm{l}^{-1}$ aquous solution of Calcofluor is basic, $(\mathrm{pH}=$ 9.6). It was not possible completely to dissolve Calcolfluor at a $1 \mathrm{~g} \cdot \mathrm{l}^{-1}$ concentration in an aqueous buffer system with a $\mathrm{pH}$ value less than 9.6. A modification of the original procedure was tried with the beer samples initially adjusted to $\mathrm{pH}=8.5$. The result (Figure 3 ) indicates a slight improvement of the correlation to the AMSmethod compared to the original CEP-method (10) in Figure 1 $(R=0.731$ compared to 0.686$)$. In some of the beers a slight haze and a darker color was observed after the adjustment of $\mathrm{pH}$.

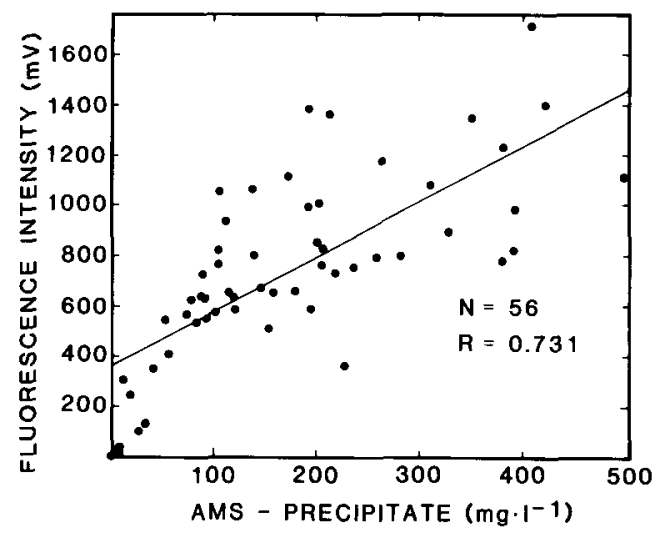

Figure 3. The relationship between $\beta$-glucan content in beer estimated by the AMS-method and the CEP-method at an adjusted $\mathrm{pH}$ of beer of $\mathrm{pH}=8.5$. Samples analysed by the method described by JENSEN and AASTRUP (10). Material from Table I. 


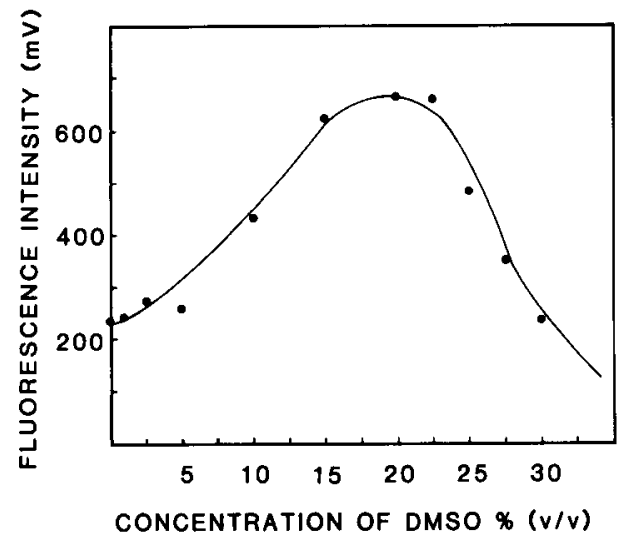

Figure 4. The effect of DMSO on the binding between Calcofluor and $\beta$-glucan. Samples were made using the original method (10), but using solutions of Calcofluor containing DMSO.

\subsubsection{The effect of Dimethylsulfoxid (DMSO) on Calcofluor binding}

In order to improve the binding of Calcofluor to $\beta$-glucan, various concentrations of DMSO were investigated. 6 samples of beer differing in $\beta$-glucan content were analysed according to the original CEP-method (10), except for the DMSO addition. It was observed that $0-20 \% \mathrm{DMSO}$ at the complex formation stage improved the binding between Calcofluor and $\beta$-glucan in a similar pattern for all 6 beers (Figure 4). The ratio Calcofluor- $\beta$-glucan increased $2-3$ fold at the optimal addition of DMSO (17.5 - 22.5\% (v/v)). Changes in $\mathrm{pH}$ at DMSO addition did not affect the fluorescence measurement and the Calcofluor binding obtained.

\subsubsection{Solubilization of the precipitated Calcofluor- $\beta$-glucan complex}

The method of JENSEN and AASTRUP (10) was designed to measure Calcofluor binding of ethanol precipitates of flour samples of barley and malt as well as of wort and beer. In order to keep the particles in suspension, a viscous $75 \%$ glycerol/water solution was used to suspend the ethanol precipitate. Air bubbles interfering with the fluorescence measurements could be eliminated by treatment in a vacuum chamber or in an ultrasonic bath. It was found that for beer and wort, the $75 \%$ glycerol solution could be ex- changed for a $0.5 \mathrm{M}$-glycine buffer, $\mathrm{pH}=10.0$, obtaining a true solution of the Calcofluor- $\beta$ glucan complex completely eliminating the heterogeneity problems (10). Phosphate and Carbonate buffers at $\mathrm{pH}=10.0$ were also tested, but fading of the Calcofluor- $\beta$-glucan fluorescence was here much more pronounced than in the glycine buffer. After continuous exposure with light at maximum excitation wavelength ( 363 $\mathrm{nm})$ for 2 hours, the fluorescence intensity of Calcofluor $\left(1 \mathrm{~g} \cdot \mathrm{l}^{-1}\right)$ in a glycine buffer at maximum emission wavelength $(425 \mathrm{~nm})$ decreased $5 \%$, as was found in glycerol suspensions. In comparison, a fading of 50 and $30 \%$ was found when using water and $0.5 \mathrm{M}$-phosphate buffer, respectively.

Fluorescence is affected by the viscosity of the solution. Consequently, it was found that fluorescence intensity of the Calcofluor- $\beta$-glucan complex in glycine buffer was about 3 times weaker than in $75 \%$ glycerol. The advantages of the glycine buffer with regard to sample solubilization of the Calcofluor- $\beta$-glucan complex were, however, decisive for the choice of the glycine buffer in the further experimental work.

\subsubsection{Temperature effects}

Temperature highly affects the binding between Calcofluor and $\beta$-glucan (Figure 5). If the

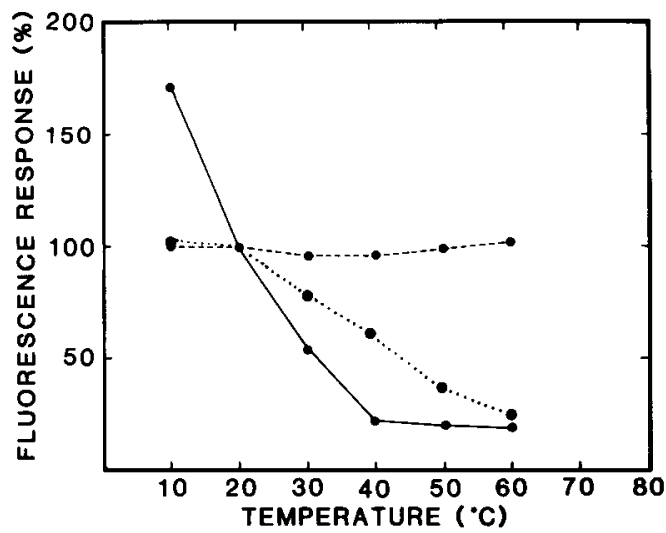

Figure 5. The effect of temperature on the binding of Calcofluor to the ethanol precipitate. Varying temperature at the complex formation stage (- $\longrightarrow$, at the ethanol precipitation stage $(\ldots \ldots \ldots \ldots)$ and at the precipitate solubilization - measuring stage (-----.-) ( glycine buffer, $\mathrm{pH}=10.0$ ). Basic temperature conditions $20^{\circ} \mathrm{C}$. Fluorescence intensity of the ethanol precipitate at normal procedure at $20^{\circ} \mathrm{C}=100 \%$. 
Calcofluor solution and beer samples were mixed and let to stand in $15 \mathrm{~min}$ at $10^{\circ} \mathrm{C}$ or $30^{\circ} \mathrm{C}$ instead of at $20^{\circ} \mathrm{C}$, followed by precipitation dissolvement in buffer and reading both at $20^{\circ} \mathrm{C}$, the fluorescence intensities obtained were found to be 170 and $55 \%$, respectively, of the response found at $20^{\circ} \mathrm{C}$. As demonstrated in Figure 5, the temperature effect at the precipitation stage was less than at complex formation, while temperature induced differences at the measurement stage were small.

\subsection{Results obtained with the optimized CEP- method}

Based on the results presented in section 3.2, the optimised CEP-method was developed (see section 2.4). It was found (3.2.3) that the binding between Calcofluor and $\beta$-glucan was more effective, if the complex was made in a solution containing DMSO. Maximum fluorescence intensity was achieved, using a Calcofluor solution containing $40 \%$ DMSO, giving a $20 \%$ solution at the complex formation stage. Further, a more convenient way of solubilizing the precipitate for spectrofluorimetric measurement was achieved using the glycine/ $\mathrm{NaOH}$ buffer (section 3.2.4).

\subsubsection{Beer}

Figure 6 describes the relationship between $\beta$-glucan content estimated with the AMS-method and the improved DMSO/Glycine CEPmethod for all beer samples tested (Table I). The correlation coefficient of 0.945 clearly represents a significant improvement of the results in Figure 1, using the original method (10). The $\beta$-glucan content of all 56 beer samples were estimated from the fluorescence measurements using the regression line with the AMS-method as standard curve. The results are listed in Table I, column 7 .

\subsubsection{Wort}

The worts described in Table II were analysed, estimating $\beta$-glucan content by the AMS-method and by the improved DMSO/glycine CEP-method. The linear correlation between the two methods was very high, $\mathrm{R}=0.996$ (Figure 7). Wort containing more than $1000 \mathrm{mg} \cdot \mathrm{l}^{-1} \beta$-glucan are rarely found, and a calculation omitting No. 23 and No. 24 (Table II) was therefore undertaken.
Still, a high correlation with the AMS-method was observed $(R=0.972)$. Estimates of the $\beta$-glucan content expressed in $\mathrm{mg} \cdot \mathrm{l}^{-1}$ AMS precipitate of the individual worts were calculated from the CEP data using the regression line (Table II). Because of an unlinearity between fluorescence intensities and concentration of fluorochrome, (tested by dilution) for fluorescence intensities greater than $1500 \mathrm{mV}$, it was necessary to dilute wort samples No. 23 and 24 with buffer 2 and 4 fold, respectively, before measurement.

\subsection{The specificity of the improved CEP- method for measuring $\beta$-glucan}

All 56 beer samples were treated with $\beta$-glucanase (section 2.6) and subsequently analysed as described in section 2.4. The results from these beers are shown as open circles in Figure 6, plotted against AMS precipitate ( $\mathrm{mg} \cdot \mathrm{l}^{-1}$ ) before enzyme treatment. It is evident that fluorescence intensity drops to a constant value close to zero independent of the amount of $\beta$-glucan initially present in the beer. Furthermore, two samples of beer (No. 30 and No. 53, Table I) were treated with $\beta$-glucanase and the $\beta$-glucan content were estimated by the AMSmethod. Estimates of 8 and $30 \mathrm{mg} \cdot \mathrm{l}^{-1} \beta$-glucan respectively, were found, which correspond to 5

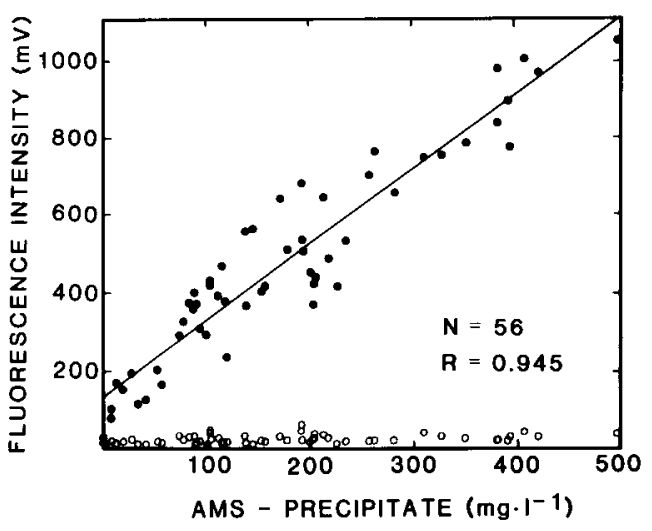

Figure 6 . The relationship between $\beta$-glucan content in beer estimated by the AMS-method and the improved CEP-method. $=$ beer sample, $O=\beta$-glucanase treated beer sample (fluorescence intensity plotted against AMS-precipitate content of the original sample). Material from Table I. 


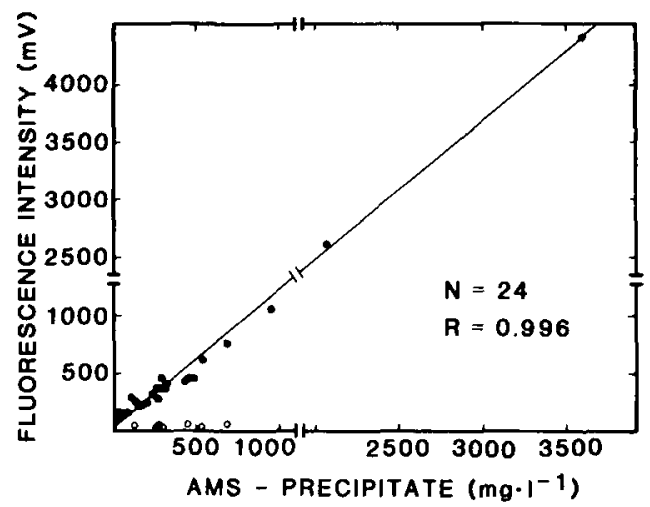

Figure 7. The relationship between $\beta$-glucan content in wort estimated by the AMS-method and by the improved CEP-method. $-=$ wort sample, $O=$ $\beta$-glucanase treated wort sample (fluorescence intensity plotted against AMS precipitate content of the original sample). Material from Table II.

and $10 \%$, respectively, of the content determined before treatment with the enzyme. In comparison, the same beer samples tested with the CEPmethod showed 6 and $3 \%$ of the levels of the untreated beers after enzyme treatment. The results suggest, that the CEP-method is highly specific for $\beta$-glucans giving lower background than the AMS-method. Eight wort samples were treated with $\beta$-glucanase and analysed by the improved method. As shown in Figure 7 (open circles), very low fluorescence intensities were recorded, indicating a high specificity of the fluorescence method also for wort.

\subsection{Viscosity of beer and wort compared with the $\boldsymbol{\beta}$-glucan determinations}

Beer viscosity data for all samples (Table I) were compared with $\beta$-glucan content estimated by the AMS- and by the improved CEP-method. The correlation coefficients between the logarithm of viscosity on one hand and the $\beta$-glucan estimated by the CEP- or the AMS-method on the other were low, $R=0.360$ and $R=0.362$, respectively. The correlation between the logarithm of viscosity and the improved CEP-method for a uniform group of beers produced in the same brewery (pilot brewery beers, Table I) was, however, found to be significantly higher $(\mathrm{N}=10$, $R=0.845$ ). The results confirm that viscosity of beer does not account for $\beta$-glucan content alone.
Other substances ( $\alpha$-dextrines, proteins) contributes to the background viscosity. These substances are probably less variable in pilot beers due to the standardized conditions of the pilot brewing.

The wort samples analysed contain much higher levels of $\beta$-glucan than does beer. The correlation between the logarithm of viscosity and $\beta$-glucan estimates obtained with the improved CEP-method and the AMS-method were found to be as high as $R=0.907$ and 0.911 , respectively, indicating that $\beta$-glucans in wort contributes to a significant part of the wort viscosity.

\subsection{Analysis of dialyzed beers}

Five beers No. 12, 24, 34, 48 and 56 (Table I) representing various levels of $\beta$-glucan content were selected for a further investigation of the CEP-method. After removal by dialysis of salts, dextrins, proteins, $\beta$-glucans etc. with molecular weight lower than 10,000 daltons, the fluorescence intensities obtained with the improved CEP-method of all samples dropped nearly to zero. A turbid solution was observed after centrifugation (section 2.4) indicating the formation of a very fine haze which was, however, not possible to precipitate by normal centrifugation $(4000 \mathrm{rpm}$.). On the other hand the $\beta$-glucan content estimated by the AMS-method decreased only $10-15 \%$ after dialysis (Figure 8 ). It was

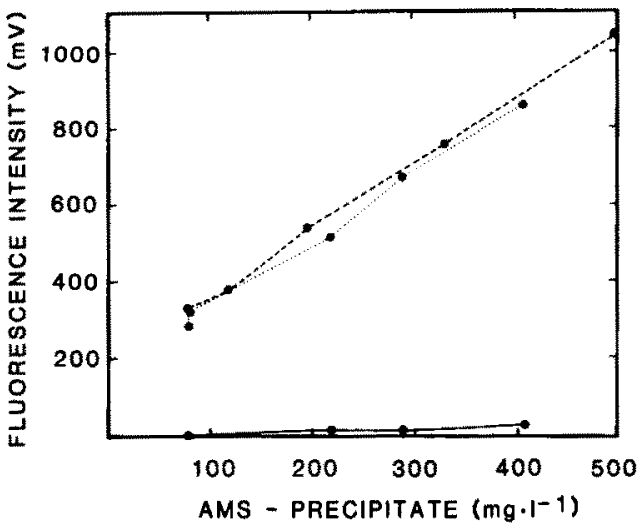

Figure 8. The effect of removal of the low molecular fraction on the CEP-measurement. $\beta$-glucan content estimated by the AMS-method is related to fluorescence intensity of the CEP-method. Dialyzed sample (——), untreated sample (-.----), dialyzed sample $+\beta$-glucanase treated beer $(\ldots \ldots \ldots \ldots)$. 
found, that by mixing the dialyzed samples with $\beta$-glucanase treated beer, the haze could be precipitated and the fluorescence intensities of the original beer samples were almost reconstituted (Figure 8 ). Likewise, by adding $20 \%$ or $10 \%$ Corn Sirup or $1 \%$ Starch solution to the dialyzed beer, Calcofluor fluorescence intensities of 80,50 and $25 \%$, respectively, of the expected fluorescence values of the intact beer was obtained. By addition of a $10 \%$ Corn Sirup solution still some haze was observed after addition of ethanol and centrifugation, but the haze was absent if a $20 \%$ Corn Sirup was added. Thus it was proved, that low molecular compounds including sugars are essential as a necessary environment for the easy precipitation of the the Calcofluor $\beta$-glucan complex in beer. It was also found, that the AMSmethod and the improved CEP-method preferentially measure $\beta$-glucan with a higher molecular weight than 10,000 daltons.

\section{DISCUSSION}

WoOD and Fulcher (16) demonstrated that Calcofluor selectively precipitates $\beta$-glucan in an aqueous system containing purified $\beta$-glucans, starch, proteins and pentosans. Moreover, WOOD (15) found that an increased ionic strength of the solvent up to a certain level increases dye binding, but prevents precipitation. At higher levels of Calcofluor, dye binding is negatively affected. The precipitation of the complex between $\mathrm{Cal}-$ cofluor and $\beta$-glucan in beer is absent or incomplete at some of the conditions prevalent in the present investigation. Beer and wort contain salts contributing to the ionic strength, which might explain the uncomplete precipitation of $\beta$-glucans by Calcofluor in a beer system. Therefore, ethanol has been used as an effective precipitation agent. In testing various factors affecting the precipitation of $\beta$-glucan with Calcofluor, WOOD and Fulcher found that $\mathrm{pH}$ (from 6 to 10) and temperature (from 5 to $25^{\circ} \mathrm{C}$ ) did not influence the complex formation and precipitation of the Calcofluor- $\beta$-glucan complex in weak buffers. In the present investigation carried out in beer and wort involving precipitation with ethanol, it was shown that both $\mathrm{pH}$ and temperature affect the binding of Calcofluor to $\beta$-glucan. A high $\mathrm{pH}(\mathrm{pH}=9)$ was more effective in binding, while an increase in temperature decreased the amount of Calcofluor bound. As mentioned a high salt concentration prevents the binding between Calcofluor and $\beta$-glucan. This salt effect is likely to be increased, if temperature is raised. A temperature increase at the time of complex formation gave less binding (Figure 8) in accordance hereto. The temperature effect observed at the precipitation stage is probably due to solubilization of the Calcofluor ethanol precipitate at higher temperatures.

Precipitation of Calcofluor bound $\beta$-glucan has also been studied in non aquous solutions. WOOD and FULCHER (16) showed that precipitation of $\beta$-glucan with Calcofluor occurs in a similar manner in $100 \%$ DMSO as in water. In the present work DMSO has been used to improve the binding between Calcofluor and $\beta$-glucan in beer and wort. The presence of DMSO at concentrations lower than $20 \%(\mathrm{v} / \mathrm{v})$ is likely to open up the $\beta$-glucan structure for Calcofluor binding, and partially neutralize the negative salt effect, while higher concentrations of DMSO are negative to Calcofluor binding to the ethanol precipitate.

There is still a limited knowledge of the nature of the Calcofluor $\beta$-glucan binding. Woov (15) suggests that binding takes place in regions of the polysaccharide of decreased polarity, and that the overall mechanism is a hydrophobic interaction. Using the binding for a quantitative measurement of $\beta$-glucans, it is evident that a controlled environment must be present to achieve that Calcofluor is bound in a reproducible ratio to the $\beta$-glucan. It was shown from the trials in section 3.2.1. that a high concentration of Calcofluor $\left(4 \mathrm{~g} \cdot \mathrm{I}^{-1}\right)$ without addition of DMSO gives a poor result compared to analysis of a low concentration of Calcofluor $\left(1 \mathrm{~g} \cdot \mathrm{l}^{-1}\right)$, Additional six samples of beer were analysed using high (4 $\left.\mathrm{g} \cdot \mathrm{1}^{-1}\right)$ and low $\left(\mathrm{g} \cdot \mathrm{l}^{-1}\right)$ concentration of Calcofluor with the addition of DMSO. It was found that the correlation between Calcofluor binding and AMS precipitate were not significantly improved at the high concentration of Calcofluor. In a study, WooD (15) demonstrated a high specificity of Calcofluor to $\beta$-glucan, among about 41 carbohydrates tested. Woov et al. (17) showed that only the presence of $\beta$-glucans induced major changes in the absorption and emission spectra of Calcofluor, when extracts of several cereal 
components were monitored, by measuring fluorescence before and after treatment with $\beta$-glucanase. These results are in agreement with the observations described in this paper. After treatment of beer or wort samples with $\beta$-glucanase, there is only a slight binding of Calcofluor to the ethanol precipitate, indicating a low background binding with Calcofluor.

It was found from the dialysis experiments (section 3.4.2) that sugars and other low molecular carbohydrates present in beer and wort were essential for a quantitative precipitation of the Calcofluor- $\beta$-glucan complex in $77 \%(v / v)$ ethanol. Without the presence of these low molecular cabohydrates, the extremely fine precipitate formed could not be separated with normal centrifugation.

In brewing it is generally accepted, that it is the high molecular $\beta$-glucans in beer and wort which are troublesome causing increased viscosity and time lag during processing (7). It was found that both the AMS- and the CEP-methods are insensitive for $\beta$-glucans with a molecular weigth lower than 10,000 dalton.

It has been shown that the AMS-procedure will not only precipitate $\beta$-glucans, but to a minor extent also other polysaccharides ( $x$-dextrines etc., 2). In the present investigation the AMS-method seems to give higher background binding compared to the CEP-method. Further experiments comparing the AMS- and the CEPmethods will be made in order to determine the degree of specificity.

It has thus been shown that the improved CEP-method is a reasonable specific measure for $\beta$-glucan in wort and beer. With this method it is possible for one person to analyse at least 50 samples of beer or wort per day, compared to 6 analysis per $1 \frac{1}{2}$ day for the AMS-method. The improved CEP-method will be further tested with regard to Calcofluor binding to $\beta$-glucans of different molecular weights.

\section{ACKNOWLEDGEMENTS}

I wish to express my sincere gratitude to Fil. Dr. LARS MUNCK for support and critical reading of the manucript. I am most grateful to M.Sc. S.AA. Jensen and cand.scient. S. Aastrup for stimulating discussions. I am indebted to M.Sc. A. KISSMEYER and KIRSTEN KIRKEGAARD for helping with the manuscript and ANNETTE HANSEN in preparing the figures. The technical assistance of LILLEMOR Frederiksen and the pleasant coorporation of eng. P. HARTLEV, LIS PEDERSEN and JøRGEN LYNG is gratefully acknowledged. The investigation is an examination work prepared for the Department of Technical Biochemistry, The Danish Technical University, Lyngby, Denmark. The support of lecturer B.B. JøRGENSEN and Professor O.B. JøRGENSEN is greatly appreciated.

\section{REFERENCES}

1. Aastrup, S., G.C. Gibbons \& L. Munck: A rapid method for estimating the degree of modification in barley malt by measurement of cell wall breakdown. Carlsberg Res. Commun., 46, 77-86 (1981)

2. Analytica EBC, Analysis Committee of European Brewing Convention, T. - M. Enari ed., Schweizer Brauerei - Rundschau, 3rd. ed., Zurich, pp. 87, (1975)

3. BAMFORTH, C.W.: Barley $\beta$-glucans, their role in malting and brewing. Brewers Digest, 22-35 (1982)

4. Crabb, D. \& G.N. Batmgate: The influence of $\beta$-glucanase on effiency of wort separation. J. Inst. Brew. 79, 519-524 (1973)

5. ERDAL, K. AND P. GJERTSEN: $\beta$-glucans in malting and brewing III. The action of endo- $\beta$ glucanases. Eur. Brew. Con. Proc. Cong., Esteril 1971, pp. 49-57 (1972)

6. FinCHER, G.B.: Morphology and chemical composition of barley endosperm cell walls. J. Inst. Brew. 81, 116-122 (1975)

7. ForREST, I.S. \& T. WAINWRIGHT: Differentiation between desirable and troublesome $\beta$-glucans. Eur. Brew. Conv. Congr. pp. 401-412 (1977)

8. ForRest, I.S. \& T. WAINWRIGHT: The mode of binding of $\beta$-glucans and pentosans in barley endosperm cell walls. J. Inst. Brew. 83, 279-286 (1977)

9. GJERTSEN, P.: Filtration of beer and factors influencing its filterability. Brewers Digest, pp. 68-70, 74-80 (1970)

10. Jensen, S.A. \& S. Aastrup: A Fluorimetric method for measuring 1,3:1,4- $\beta$-glucans in beer, wort, malt and barley by use of Calcofluor. Carlsberg Res. Commun. 46, 87-95 (1981)

11. Madecsi, J.P., F.W. Parish \& E.J. Roberts: Non-enzymic method for determination of $\beta$-glucan in the presence of starch. U. S. Dep. of Agriculture, New Orleans (1983) 
12. Preece, I.A. \& K.G. MacKenzie: Non-starchy polysaccharides of cereal grains I. Fractionation of the barley gums. J. Inst. Brew. 58, 353-362 (1952)

13. Scott, R.W: The viscosity of worts in relation to their content of $\beta$-glucans. J. Inst. Brew. 78, 179186 (1972)

14. Takayanagi, S., M. amatta, K. Satake, Y. Kuroiva, H. Igarashi \& A. Murata: Studies on frozen beer precipitates. I. Formation and general characters. J. Inst. Brew. 75, 284-292 (1969)
15. WOOD, P.J.: Specificity in the interaction of direct dyes with polysaccharides. Carbohydr. Res. 94, 271-287 (1980)

16. WOOD, P.J. \& R.G. Fulcher: Interaction of some dyes with cereal $\beta$-glucans. Cereal Chem. 55, 952-966 (1978)

17. Wood, P.J., R.G. Fulcher \& B.A. Stone: Studies on the specifity of interaction of cereal cell wall component with Congo Red and Calcofluor. Specific detection and histochemistry of $(1 \rightarrow 3),(1 \rightarrow 4)$ B-D-glucan. J. Cereal Science 1, 95$110(1983)$ 